Published in final edited form as:

Contraception. 2015 August ; 92(2): 143-151. doi:10.1016/j.contraception.2015.04.002.

\title{
Provider barriers to family planning access in urban Kenya
}

\author{
Katherine Tumlinson, PhDa, ${ }^{a}$, Chinelo C. Okigbo, MBBS, MPH ${ }^{b, c}$, and llene S. Speizer, \\ $\mathrm{PhD}$,c \\ a Office of Population Research at Princeton University, Princeton, NJ \\ b Carolina Population Center at The University of North Carolina at Chapel Hill, Chapel Hill, NC \\ c Department of Maternal \& Child Health, Gillings School of Global Public Health, The University \\ of North Carolina at Chapel Hill, Chapel Hill, NC
}

\begin{abstract}
Objective-A better understanding of the prevalence of service provider-imposed barriers to family planning can inform programs intended to increase contraceptive use. This study, based on data from urban Kenya, describes the frequency of provider self-reported restrictions related to clients' age, parity, marital status, and third party consent, and considers the impact of facility type and training on restrictive practices.
\end{abstract}

Study Design-Trained data collectors interviewed 676 service providers at 273 health care facilities in five Kenyan cities. Service providers were asked questions about their background and training and were also asked about age, marital, parity, or consent requirements for providing family planning services.

Results-More than half of providers (58\%) reported imposing minimum age restrictions on one or more methods. These restrictions were commonly imposed on clients seeking injectables, a popular method in urban Kenya, with large numbers refusing to offer injectables to women younger than twenty years. Forty-one percent of providers reported they would not offer one or more methods to nulliparous women and more than one in four providers reported they would not offer the injectable to women without at least one child. Providers at private facilities were significantly more likely to impose barriers, across all method types, and those without in-service training on family planning provision had a significantly higher prevalence of imposing parity, marital, and consent barriers across most methods.

Conclusion-Programs need to address provider-imposed barriers that reduce access to contraceptive methods particularly among young, lower parity, and single women. Promising strategies include targeting private facility providers and increasing the prevalence of in-service training.

"Corresponding author at: Office of Population Research, 228 Wallace Hall, Princeton, NJ 08544. Tel.: +1 9198244722 ; fax +1 609 258 1039; kt10@princeton.edu..

Publisher's Disclaimer: This is a PDF file of an unedited manuscript that has been accepted for publication. As a service to our customers we are providing this early version of the manuscript. The manuscript will undergo copyediting, typesetting, and review of the resulting proof before it is published in its final citable form. Please note that during the production process errors may be discovered which could affect the content, and all legal disclaimers that apply to the journal pertain. 


\section{Keywords}

Provider barriers/restrictions; contraceptive access; Kenya

\section{Introduction}

Family planning plays a critical role in protecting maternal and child health in many developing countries, yet the prevalence of contraceptive use often fails to keep pace with demand in resource constrained settings [1]. Sexually active women who wish to prevent or delay future pregnancy but are not using any method of contraception experience an unmet need for family planning [1-3]. In Kenya, approximately 39 percent of reproductive age women married or in union use modern contraceptive methods while another 26 percent have an unmet need for family planning. [4].

Women who are motivated to prevent pregnancy and able to reach a service delivery point may still encounter difficulty accessing family planning services due to medical barriers. Medical barriers are medically unnecessary restrictions that prevent or reduce access to family planning services [5,6]. One way in which providers can impose medical barriers is through the use of eligibility criteria. Medically unnecessary restrictions placed on the eligibility of some clients to receive certain types of modern methods may prevent women from receiving their preferred method or any method at all [6]. Eligibility restrictions are often based on an individual's demographic characteristics such as age, marital status, or parity $[5,6]$.

Prior studies have documented the use of such eligibility criteria in parts of sub-Saharan Africa. Speizer et al. (2000) conducted a study among Tanzanian service providers and found that many providers restricted access to modern methods such as pills, injectables, and intrauterine devices (IUCDs) based on age, with a minimum age restriction of 14-15 years and a maximum age restriction of 43-44 years [7]. Results from a recent (2014) study in urban Senegal found that approximately half of providers impose minimum age restrictions with a median minimum age of 18 years [8]. In a study conducted in Ghana, Stanback and Twum-Baah (2001) found that providers restricted the provision of injectables to those 30 years and older [9]. Restrictions based on parity were the most common eligibility criterion in the Ghana study where many providers were concerned about infertility as a complication of using modern methods and as such restricted provision to women with proven fertility - a minimum parity of three children [9]. In the Tanzania study, providers had a mean parity restriction of about 2.5 children for pills, condoms, IUCDs, and injectables [7]. Unmarried women also face barriers; in both the Ghana and Tanzania studies, providers required marriage as an eligibility criterion for reversible methods [7, 9] or required husband's consent for provision of any of the methods [7] and in the Senegal study more than one-fifth of providers in private facilities were unwilling to provide pills, injectables, or implants to unmarried women [8]. In Tanzania, the authors found that recent in-service training did not reduce provider-imposed barriers [7].

To better understand one of the possible factors affecting the persistent unmet need for family planning in Kenya, this study describes the prevalence of provider-imposed 
eligibility barriers among Kenyan service providers in public and private health care facilities in select urban areas of Kenya. Specifically, this study examines the frequency of restricted access to modern contraception based on the client's age, parity, marital status, or consent by a third party such as a husband or mother-in-law.

\section{Materials and Methods}

This analysis uses facility-level data collected in select urban areas of Kenya in 2011 by the Measurement, Learning \& Evaluation Project as part of an evaluation of the Urban Reproductive Health Initiative (Urban RH Initiative) funded by the Bill \& Melinda Gates Foundation and implemented in Kenya, Nigeria, Senegal, and Uttar Pradesh, India. The Kenya Urban RH Initiative is called Tupange and is led by Jhpiego, an affiliate of the Johns Hopkins University.

In Kenya, data were collected in five urban areas (Nairobi, Mombasa, Kisumu, Machakos, and Kakamega) between August and November 2011 and a total of 286 service delivery points were targeted for facility-level data collection. These service delivery points included hospitals, health centers, and clinics that offer family planning or maternal and child health services. Selected facilities included those where the Tupange initiative planned to implement quality improvement activities as well as those facilities identified by women in a 2010 individual-level survey as locations where they go for family planning services. Of the 286 selected facilities, a small number refused participation or had incomplete provider interviews; the final sample includes 273 facilities. Three types of facility-level data were collected: facility audits, provider interviews, and client exit interviews. This analysis utilizes data from the facility audits and provider interviews.

The facility audit was conducted by a trained data collector in collaboration with the facility manager. Data were collected on the types of services provided, integration of family planning into other health care services, and the provision and availability of different family planning methods as well as method procurement procedures and current price. With respect to this analysis, facility managers were asked if their facility provides each of 12 available family planning methods and whether the facility has any requirements for another person's consent to provide the method.

Up to four health care providers at each facility were asked to participate in the survey through an informed consent process ${ }^{1}$. These providers were asked questions on their background, preand in-service trainings, and numerous aspects of service delivery including any method provision requirements related to age, parity, marital status, or third party consent. A total of 692 providers were selected for interview; 676 providers offered at least one of the methods included in this study, had non-missing information, and are therefore included in this analysis.

This analysis investigates the prevalence of eligibility barriers related to age, parity, marital status, and third party consent with respect to seven modern methods in urban Kenya: pills,

\footnotetext{
${ }^{1}$ In facilities with five or more providers, four providers were chosen at random to participate.
} 
injectables, condoms, emergency contraceptive pills (ECP), implants, IUCDs, and female sterilization. Age and parity eligibility barriers for this analysis were defined based on the National Family Planning Guidelines for Service Providers published by Kenya's Ministry of Public Health and Sanitation [10]. According to these guidelines, all of the methods evaluated in this analysis are considered appropriate for women of reproductive age (15 to 49 years), irrespective of parity ${ }^{2}$. Therefore, minimum and maximum age barriers for all methods included in this analysis were defined as occurring if providers reported refusing methods to women older than 14 years or younger than 50 years. Providers who reported imposing barriers based on a minimum number of children or marital status were considered to impose parity or marital barriers, respectively. Those who reported requiring permission from a third party, such as a husband or mother-in-law, were defined as imposing consent barriers. All statistical tabulations were performed using Stata 11 statistical software [11]. The University of North Carolina at Chapel Hill and the Kenya Medical Research Institute reviewed and approved the study protocol and the informed consent process.

\section{Results}

The health care providers included in this analysis were primarily female ( 72 percent) and, on average, 38 years of age (Table 1). The vast majority ( 95 percent) of providers identified as Catholic or Protestant/other Christian. Most (69 percent) were registered or community nurses, with only 3 percent of participating providers holding a medical degree. Half of all participants had 10 or more years of experience and 85 percent had received pre-service training that covered family planning counseling. About half (49 percent) of providers had received in-service training on family planning provision and only one third of these (35 percent) had received this training in the previous year. On average, participants received inservice training on family planning provision two years ago; however for 12 percent of providers, more than five years had passed since this training took place. For those providers whose in-service family planning training included family planning counseling ( 89 percent), the training took place, on average, three years ago. Participating providers were fairly evenly split between public (43 percent) and private (57 percent) facilities and most (84 percent) worked in Nairobi, Mombasa, or Kisumu.

Table 2 presents the percentage of providers who restrict available methods for reasons including age, parity, marital status, and lack of third party consent. Minimum age barriers for one or more methods were reported by 58 percent of providers and nearly 60 percent of providers who offer female sterilization report restricting to women above a certain age. For most methods, the average age below which a provider will not offer a method (among those who restrict on minimum age) ranges between 18 and 21 years (Table 2a). For female sterilization, the mean minimum age was 29 years. With respect to older women, 45 percent of providers restricted access to modern contraception based on a maximum age (not including women 50 years of age or older), with pills and injectables most commonly restricted for this reason (Table 2). For all methods, the average age above which providers reportedly will not offer a method ranged between 41 and 43 years (Table 2a).

\footnotetext{
${ }^{2}$ The guidelines recommend additional counseling and follow-up when providing the IUCD to nulliparous women or women under 20 years of age and when providing injectables to women younger than 18 or older than 45 .
} 
Forty-one percent of providers restricted access to one or more methods based on parity, with large differences seen based on method type: less than two percent of providers restricted access to condoms or ECP while 60 percent restricted access to female sterilization based on parity (Table 2). Of those providers that restrict on parity, for most methods more than half of providers report that they require a minimum of one child before they will offer the method (Table $2 b$ ). For female sterilization, 46 percent of providers (among those that offer sterilization and restrict on parity) require a woman to have at least three or more children before receiving the method.

Approximately 22 percent of providers reportedly will not offer one or more methods to unmarried women (Table 2). With respect to method type, very few providers restricted access to pills, ECP, or condoms based on marital status. Approximately 10 percent report that they would not provide injectables, IUCDs, or implants to unmarried women while 40 percent would not provide female sterilization to women who are not married.

Approximately 35 percent of providers require family planning clients to have permission from a third party before providing one or more methods (Table 2). Once again, this barrier was less commonly applied to condoms and ECP. Third party consent was more often required for long acting methods and female sterilization. When asking facility managers about requirements for third party consent, between two and seven percent of facilities reported such practices for all but one method in this analysis; 54 percent of facility managers report that third party consent is required for female sterilization (Table 2c).

We also considered whether certain characteristics of providers, such as facility type or inservice training, might result in a greater likelihood of imposing unnecessary eligibility criteria. When comparing providers working at public and private facilities, a significantly higher percentage of providers in private facilities imposed minimum age restrictions across all methods (Table 3 ). For example, close to 55 percent of providers in private facilities compared to about 27 percent of providers at public facilities reported imposing minimum age restrictions on implants and IUCDs. Differences were also observed between public and private facility providers for eligibility criteria related to maximum age, parity, marital status, and third party consent. For parity, marital, and consent requirements, differences in restrictions between public and private facility providers were consistently larger for implants and IUCDs compared to the other five methods measured.

Table 4 presents the prevalence of medical barriers, stratified by whether or not the provider ever received in-service training on family planning provision. With respect to age-related barriers, significant differences based on training were limited to long acting reversible methods. Significant differences emerged for restrictions related to parity, marital status, and third party consent; for all methods except condoms and ECP, providers without in-service training on FP provision were significantly more likely to impose restrictions based on marital status and consent. Significant differences were also observed in parity-related restrictions for most methods. 


\section{Discussion}

In Kenya, unmet need for family planning remains high with about a quarter of women married or in union reporting a desire to delay or stop childbearing and being non-users of a family planning method [4]. The most common method used in urban Kenya is the injectable and this analysis shows that providers impose considerable barriers to providing this method that is particularly popular among younger users [12]. Our analysis demonstrates that about two-fifths of providers in public and private facilities impose minimum age restrictions on access to injectable contraceptives; this may have serious implications for young people's use of this method. Moreover, we demonstrate that about 20 percent of providers impose minimum age restrictions on access to condoms, the other important method for young people for unintended pregnancy and disease prevention. An additional barrier to injectable contraceptives, especially for young people, is the parity restriction whereby providers expect a woman to have had at least one child before adoption of injections. Minimum age barriers for the oral contraceptive pill are also observed at similar levels to injectables, however, this likely has less influence on adolescents' and young peoples' use since this method is less common in urban Kenya than injectables [12].

On the other end of the reproductive-age spectrum, providers also restrict access to women in the latter part of the reproductive ages. About 45 percent of providers restricted access to pills and injectables based on a maximum age with many providers limiting use of these methods among women over age 41 . While less common, restrictions based on parity and consent also influence these older women who may be seeking a long-acting or permanent method to delay or prevent a subsequent birth or may be seeking to use a method covertly if their husbands do not approve.

An important direction of programs in Kenya intended to reduce maternal mortality, unmet need, and rapid population growth is promotion of long-acting and permanent method use [13]. As seen here, these methods are not easily accessible to women who want to receive them due to provider imposed minimum and maximum age restrictions, parity restrictions, and marital status restrictions; these restrictions are particularly common among providers in private facilities and those without in-service training on family planning provision.

Our findings on provider imposed eligibility criteria based on age, parity, marital status and consent are similar to studies from Ghana [9], Senegal [8], and Tanzania [7]. As shown in those three contexts, providers in urban Kenya are imposing barriers to use, particularly for younger or unmarried women. In contrast to the Tanzania study, in-service training appears to reduce provider-imposed barriers related to parity, marital status, and third party consent.

This study is not without limitations. First, because the restrictions are based on self-reports, the information provided may be biased. In particular, provider self-reports may reflect true provider behaviors or may reflect behaviors providers believe are deemed socially acceptable. Further, the information on maximum age is harder to interpret as some providers may be referring to the age at which a woman is no longer fecund, since menopause was not offered as a response option. That said, mean ages around 41 are clearly below the age of menopause. To better know if restrictions exist, mystery client interviews 
or provider-client observations may be necessary; the mystery client approach was used in an earlier mixed-methods study from the urban area of Kisumu in Western Kenya and demonstrated the existence of eligibility restrictions related to menstrual, age, and parity requirements [14]. Second, these data do not represent urban Kenya generally. This is because the study did not include a census of facilities in Nairobi and Mombasa and did not include facilities from other cities not among the five target study cities. The sample included was selected to represent facilities where the Tupange program intended to work and facilities where women in the household survey go for family planning services. Finally, while the sample of providers included was a self-weighting sample such that larger facilities had more providers (up to four) and smaller facilities had fewer, the providers included represented those on duty during regular business hours and thus would not include those who serve the facilities on overnight or weekend shifts. This will not bias the results significantly since family planning services are usually provided as routine services; however, only a small percentage of providers surveyed were doctors and medical or clinical officers.

To conclude, these findings demonstrate that in urban settings of Kenya, provider imposed eligibility restrictions may contribute to unmet need and are more frequently practiced in private facilities and among providers lacking in-service training in family planning provision. Programs seeking to increase contraceptive use, particularly for the unmarried and young, need to consider training providers that these young people should have access to injectables, IUCD, and implants without any restrictions. These types of provider training programs may lead to greater access to the most effective methods for young people to delay a first birth and to space births, increasing educational opportunities for young people and reducing unintended pregnancy and maternal mortality in Kenya.

\section{Acknowledgements}

This research was supported by a grant awarded to the Carolina Population Center (CPC) at The University of North Carolina at Chapel Hill by the Bill \& Melinda Gates Foundation. We are also grateful to CPC (R24 HD050924) for general support. The contents of this article are solely the responsibility of the authors and do not necessarily represent the official views of CPC or the Bill \& Melinda Gates Foundation.

\section{References}

1. Cleland J, Bernstein S, Ezeh A, Faundes A, Glasier A, Innis J. Family planning: the unfinished agenda. Lancet. 2006; 368:1810-27. [PubMed: 17113431]

2. Darroch JE, Singh S. Trends in contraceptive need and use in developing countries in 2003, 2008, and 2012: an analysis of national surveys. Lancet. 2013; 381:1756-62. [PubMed: 23683642]

3. World Health Organization. [January 9, 2015] Unmet need for family planning. 2013. Available from: http://www.who.int/reproductivehealth/topics/family_planning/unmet_need_fp/en/.

4. Population Reference Bureau. Family Planning Worldwide: 2013 Data Sheet. Washington, DC: 2013.

5. Bertrand JT, Hardee K, Magnani RJ, Angle MA. Access, quality of care and medical barriers in family planning programs. Int Fam Plan Perspect. 1995; 21:64-74.

6. Shelton JD, Angle MA, Jacobstein RA. Medical barriers to access to family planning. Lancet. 1992; 340:1334-5. [PubMed: 1360046]

7. Speizer IS, Hotchkiss DR, Magnani RJ, Hubbard B, Nelson K. Do service providers in Tanzania unnecessarily restrict clients' access to contraceptive methods? Int Perspect Sex Reprod Health. $2000 ; 26: 13-42$. 
8. Sidze EM, Lardoux Sn, Speizer IS, Faye CM, Mutua MM, Badji F. Young Women's Access to and Use of Contraceptives: The Role of Providers' Restrictions in Urban Senegal. Int Perspect Sex Reprod Health. 2014; 40:176-83. [PubMed: 25565345]

9. Stanback J, Twum-Baah KA. Why do family planning providers restrict access to services? An examination in Ghana. Int Perspect Sex Reprod Health. 2001; 27:37-41.

10. Kenya Ministry of Public Health and Sanitation. National Family Planning Guidelines for Service Providers. 4th ed.. Division of Reproductive Health; Nairobi, Kenya: 2010.

11. StataCorp. Stata Statistical Software: Release 11. StataCorp LP; College Station, TX: 2009.

12. Kenya National Bureau of Statistics (KNBS) and ICF Macro. Kenya Demographic and Health Survey 2008-09. KNBS and ICF Macro; Calverton, Maryland: 2010.

13. Ministry of Public Health and Sanitation Division of Reproductive Health. [March 19, 2015] Strategy for Improving the Uptake of Long-Acting and Permanent Methods of Contraception in the Family Planning Program. 2008. Available from: https://www.k4health.org/sites/default/files/ Kenya LAPM Strategy.pdf

14. Tumlinson K, Speizer I, Archer L, Behets F. Simulated clients reveal programmatic factors that may influence contraceptive use in Kisumu, Kenya. Glob Health Sci Pract. 2013; 1:407-16. [PubMed: 24683525] 


\section{Implications}

Providers frequently impose medically unnecessary eligibility restrictions on young, unmarried, and nulliparous women in urban Kenya; restrictions are often higher for long acting and permanent methods. Private facility providers and those lacking in-service training on family planning provision are more likely to unnecessarily restrict contraceptive access. 


\section{Table 1}

Background and training characteristics of health care providers in 273 public and private health care facilities in select urban areas of Kenya, 2011.

\begin{tabular}{|c|c|c|}
\hline & $\mathrm{N}=676$ & $\%$ \\
\hline \multicolumn{3}{|l|}{ Age } \\
\hline $21-29$ & 218 & $32 \%$ \\
\hline $30-39$ & 196 & $29 \%$ \\
\hline $40-49$ & 143 & $21 \%$ \\
\hline $50+$ & 119 & $18 \%$ \\
\hline Mean age in years (range) & $38(21-72)$ & \\
\hline \multicolumn{3}{|l|}{ Gender } \\
\hline Female & 487 & $72 \%$ \\
\hline Male & 188 & $28 \%$ \\
\hline Missing & 1 & $0 \%$ \\
\hline \multicolumn{3}{|l|}{ Religion } \\
\hline Catholic & 188 & $28 \%$ \\
\hline Protestant/other Christian & 457 & $68 \%$ \\
\hline Muslim/none/other & 31 & $5 \%$ \\
\hline \multicolumn{3}{|l|}{ Cadre of Staff } \\
\hline Doctor & 18 & $3 \%$ \\
\hline Medical or Clinical Officer & 115 & $17 \%$ \\
\hline Registered Nurse & 282 & $42 \%$ \\
\hline Community Nurse & 184 & $27 \%$ \\
\hline VCT Provider/other & 77 & $11 \%$ \\
\hline \multicolumn{3}{|l|}{ Years working as a health care provider } \\
\hline Less than two years & 71 & $11 \%$ \\
\hline Two to four years & 143 & $21 \%$ \\
\hline Five to nine years & 126 & $19 \%$ \\
\hline 10 to 19 years & 135 & $20 \%$ \\
\hline 20 or more years & 200 & $30 \%$ \\
\hline Missing & 1 & $0 \%$ \\
\hline Mean years as a health care provider (range) & $13(0-50)$ & \\
\hline \multicolumn{3}{|l|}{ Pre-service training covered FP counseling } \\
\hline Yes & 576 & $85 \%$ \\
\hline No & 84 & $12 \%$ \\
\hline Missing & 16 & $2 \%$ \\
\hline \multicolumn{3}{|c|}{ Provider received in-service training on FP provision } \\
\hline Yes & 334 & $49 \%$ \\
\hline No & 342 & $51 \%$ \\
\hline
\end{tabular}




\begin{tabular}{lll}
\hline & $\mathbf{N}=\mathbf{6 7 6}$ & $\mathbf{\%}$ \\
\hline Years since in-service training on FP provision & $\mathrm{n}=334$ & $\%$ \\
Less than one year & 117 & $35 \%$ \\
One to four years & 157 & $47 \%$ \\
Five or more years & 41 & $12 \%$ \\
Missing & 19 & $6 \%$ \\
Mean years since in-service training on FP provision & $2(0-29)$ & \\
\hline Provider received in-service training on FP counseling & $\mathrm{n}=334$ & $\%$ \\
Yes & 296 & $89 \%$ \\
No & 37 & $11 \%$ \\
Missing & 1 & $0 \%$ \\
\hline Years since in-service training on FP counseling & $\mathrm{n}=296$ & $\%$ \\
Less than one year & 86 & $29 \%$ \\
One to four years & 162 & $55 \%$ \\
Five or more years & 41 & $14 \%$ \\
Missing & 7 & $2 \%$ \\
Mean years since in-service training on FP counseling & $3(0-31)$ & \\
\hline Facility type & & \\
Public & 294 & $43 \%$ \\
Private & 382 & $57 \%$ \\
\hline Location of facility & & \\
Nairobi & 149 \\
Mombasa & $53 \%$ \\
Kisumu & 55 & $21 \%$ \\
Machakos & & \\
Kakamega & & $84 \%$ \\
\hline
\end{tabular}




\section{Table 2}

Family planning providers' self-reported restrictions based on the client's age, parity, marital status, or the consent of a third party, by contraceptive method in select urban areas of Kenya, 2011.

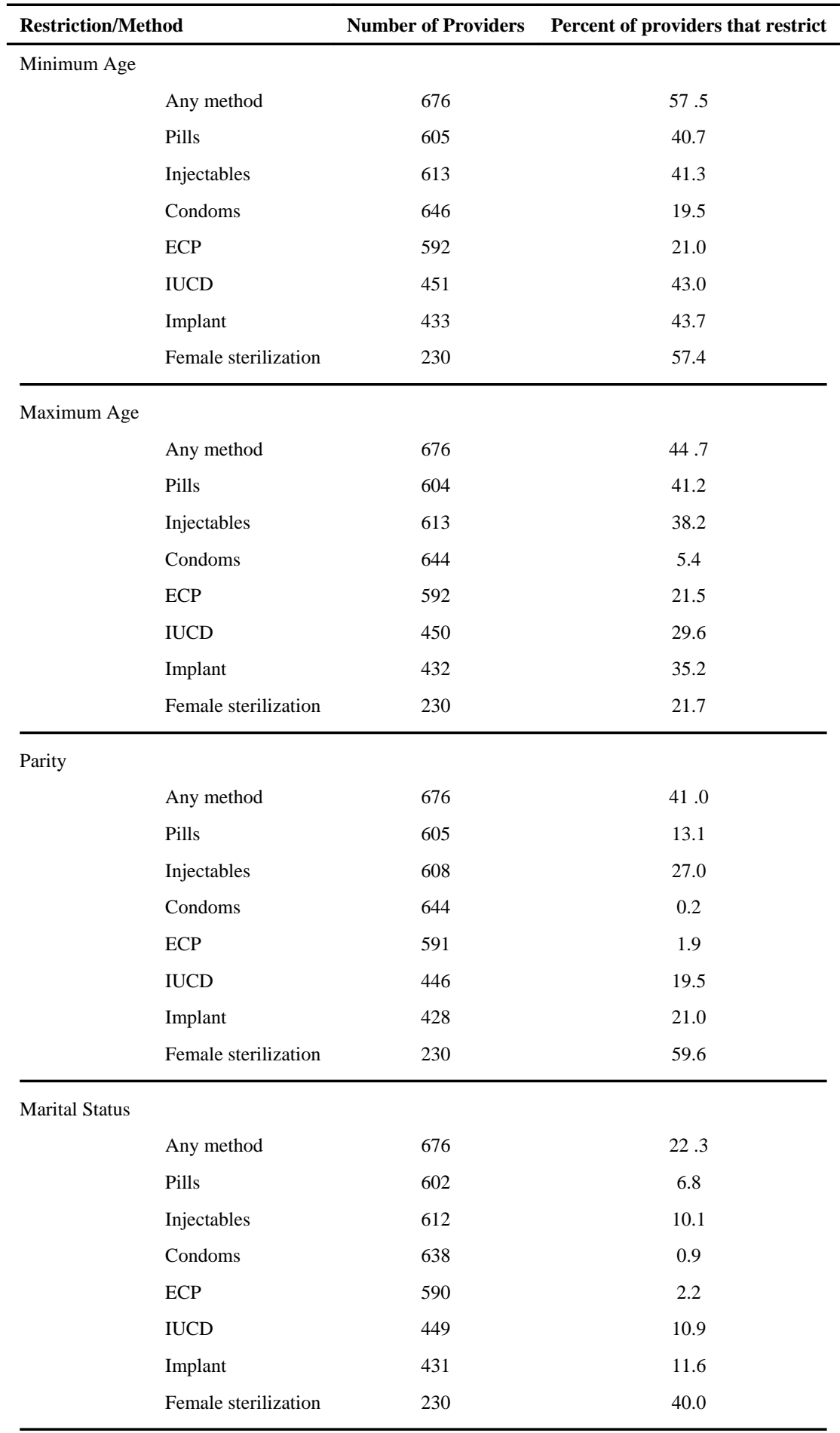

Contraception. Author manuscript; available in PMC 2016 August 01. 


\begin{tabular}{|c|c|c|}
\hline Restriction/Method & Number of Providers & Percent of providers that restrict \\
\hline \multicolumn{3}{|l|}{ Consent } \\
\hline Any method & 676 & 35.4 \\
\hline Pills & 599 & 9.2 \\
\hline Injectables & 611 & 9.8 \\
\hline Condoms & 636 & 3.1 \\
\hline $\mathrm{ECP}$ & 590 & 4.2 \\
\hline IUCD & 447 & 17.5 \\
\hline Implant & 432 & 16.9 \\
\hline Female sterilization & 229 & 68.1 \\
\hline
\end{tabular}

Note: Not all providers offer all methods of family planning; therefore sample sizes vary by method

Note: Variation in sample sizes within methods reflect nonresponse or missing data for some questions 


\section{Table 2a}

Mean age restrictions, by method, in select urban areas of Kenya, 2011.

\begin{tabular}{|c|c|c|c|c|c|c|}
\hline \multirow[b]{2}{*}{ Method } & \multirow{2}{*}{$\begin{array}{c}\text { Number of } \\
\text { providers who } \\
\text { offer and restrict } \\
\text { on minimum age }\end{array}$} & \multicolumn{2}{|c|}{$\begin{array}{l}\text { Age below which providers will } \\
\text { not offer this method }\end{array}$} & \multirow{2}{*}{$\begin{array}{c}\text { Number of } \\
\text { providers who } \\
\text { offer and restrict } \\
\text { on maximum age }\end{array}$} & \multicolumn{2}{|c|}{$\begin{array}{l}\text { Age above which providers will } \\
\text { not offer this method }\end{array}$} \\
\hline & & Mean & Range & & Mean & Range \\
\hline Pills & 246 & 19 & $(15-35)$ & 249 & 41 & $(20-49)$ \\
\hline Injectables & 253 & 20 & $(15-36)$ & 234 & 42 & $(25-49)$ \\
\hline Condoms & 126 & 18 & $(15-35)$ & 35 & 41 & $(20-49)$ \\
\hline ECP & 124 & 18 & $(15-30)$ & 127 & 42 & $(20-49)$ \\
\hline IUCD & 194 & 21 & $(15-35)$ & 133 & 42 & $(20-49)$ \\
\hline Implant & 189 & 20 & $(15-35)$ & 152 & 42 & $(30-49)$ \\
\hline Female sterilization & 132 & 29 & $(15-40)$ & 50 & 43 & $(30-49)$ \\
\hline
\end{tabular}




\section{Table 2b}

Number of family planning providers who provide each method and who restrict clients' eligibility for reasons of parity, by method, in select urban areas of Kenya, 2011.

\begin{tabular}{|c|c|c|c|c|c|c|}
\hline \multirow[t]{2}{*}{ Method } & \multirow{2}{*}{$\begin{array}{l}\text { Number of } \\
\text { providers } \\
\text { that provide } \\
\text { method }\end{array}$} & \multirow{2}{*}{$\begin{array}{c}\text { Percent of } \\
\text { providers that } \\
\text { restrict } \\
\text { method based } \\
\text { on parity }\end{array}$} & \multirow{2}{*}{$\begin{array}{l}\text { Number of } \\
\text { providers } \\
\text { who restrict }\end{array}$} & \multicolumn{3}{|c|}{$\begin{array}{l}\text { Of the providers that restrict, percent that report the } \\
\text { minimum number of children a client must have }\end{array}$} \\
\hline & & & & One child & Two children & $\begin{array}{l}\text { Three or more } \\
\text { children }\end{array}$ \\
\hline Pills & 605 & 13.1 & 79 & 63.3 & 20.3 & 16.5 \\
\hline Injectables & 608 & 27.0 & 164 & 58.5 & 27.4 & 14.0 \\
\hline Condoms & 644 & 0.2 & 1 & 0.0 & 0.0 & 100.0 \\
\hline $\mathrm{ECP}$ & 591 & 1.9 & $11^{*}$ & 50.0 & 50.0 & 0.0 \\
\hline IUCD & 446 & 19.5 & $87^{€}$ & 55.8 & 33.7 & 10.5 \\
\hline Implant & 428 & 21.0 & $90^{¥}$ & 56.2 & 32.6 & 11.2 \\
\hline Female sterilization & 230 & 59.6 & $137^{£}$ & 22.0 & 32.6 & 45.5 \\
\hline \multicolumn{7}{|c|}{ One of these providers has missing data; percent reporting minimum number reflects sample size of 10} \\
\hline
\end{tabular}




\section{Table 2c}

Number of health care facilities that provide each method and percent where facility manager reports restricting clients' eligibility to use a method without consent of a third party, by method type, in select urban areas of Kenya, 2011.

\begin{tabular}{lcc}
\hline Method & Number of facilities that provide method & $\begin{array}{c}\text { Percent of facilities that restrict method provision to clients with third } \\
\text { party consent }\end{array}$ \\
\hline Pills & 250 & 5.2 \\
Injectables & 253 & 4.7 \\
Condoms & 240 & 2.1 \\
ECP & 221 & 5.0 \\
IUCD & 156 & 7.1 \\
Implant & 153 & 7.2 \\
Female sterilization & 52 & 53.9 \\
\hline
\end{tabular}


Table 3

Family planning providers' self-reported restrictions based on the client's age, parity, marital status, or the consent of a third party, by contraceptive method and facility type in select urban areas of Kenya, 2011.

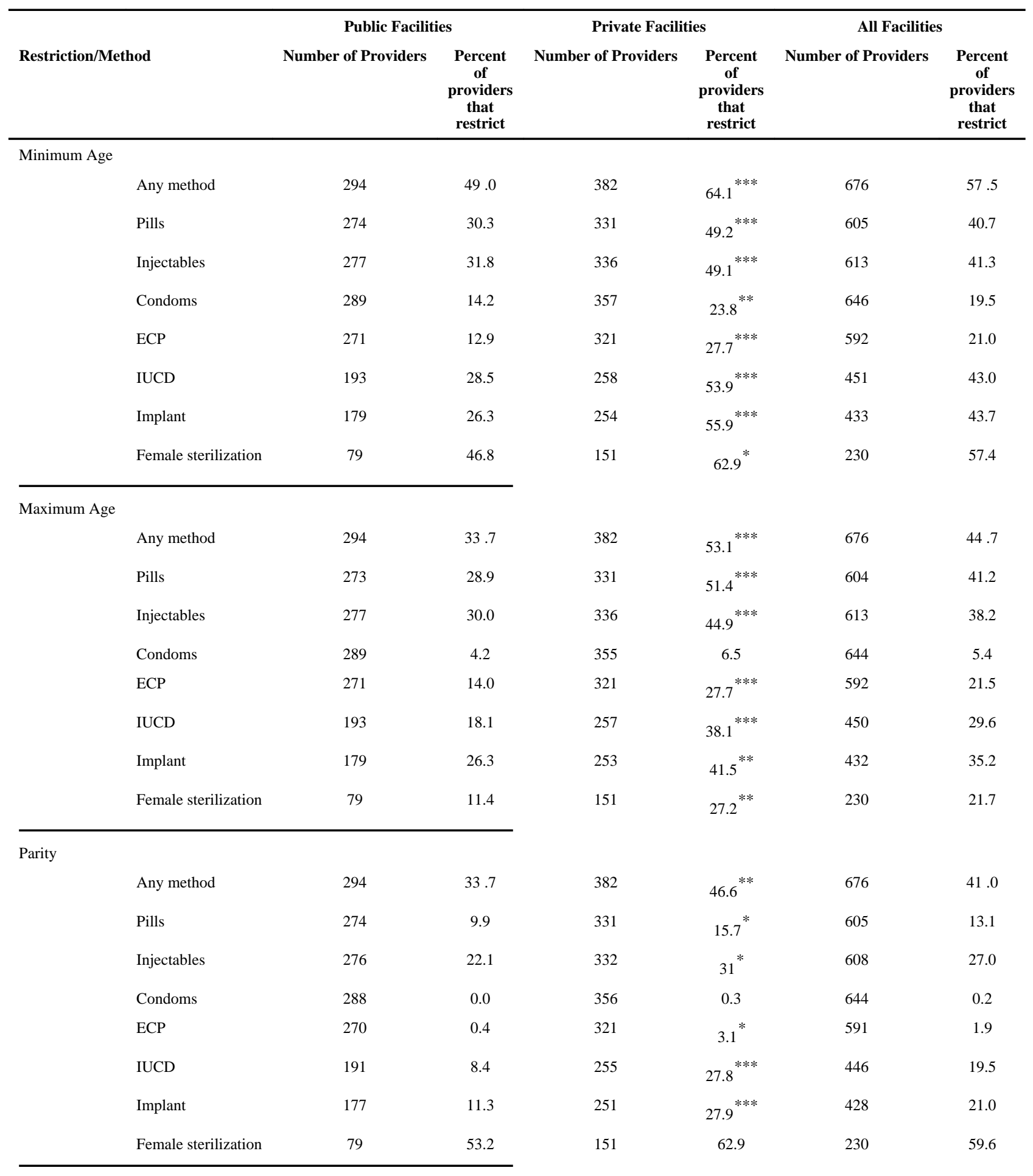




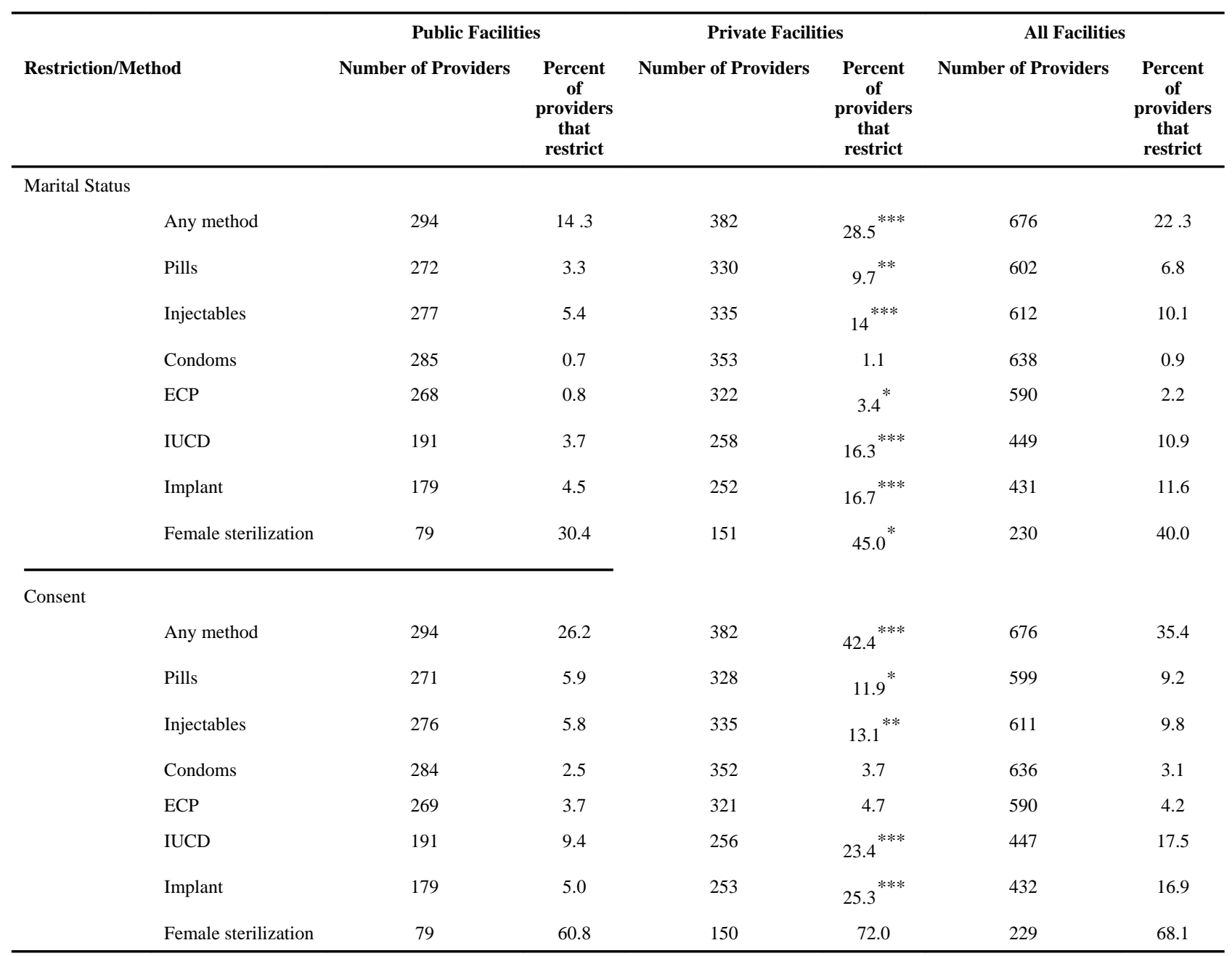

Note: Not all providers offer all methods of family planning; therefore sample sizes vary by method

Note: Variation in sample sizes within methods reflect nonresponse or missing data for some questions

* Chi-square test significant at $\mathrm{p}<.05$

*** $<$ <.01

$* * *$

$\mathrm{p}<.001$ between public and private facilities 


\section{Table 4}

Family planning providers' self-reported restrictions based on the client's age, parity, marital status, or the consent of a third party, by contraceptive method and in-service training in family planning provision; select urban areas of Kenya, 2011.

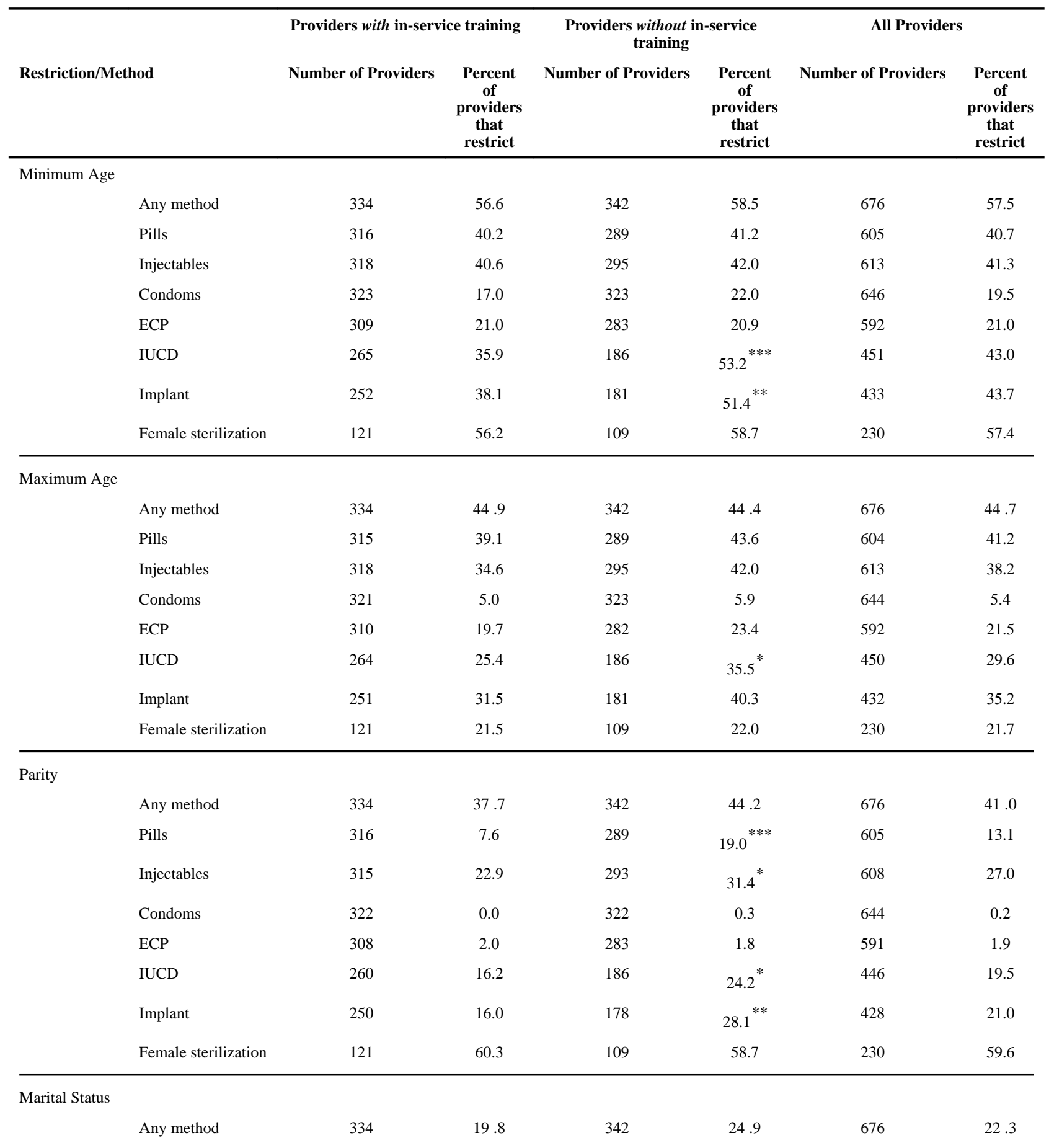




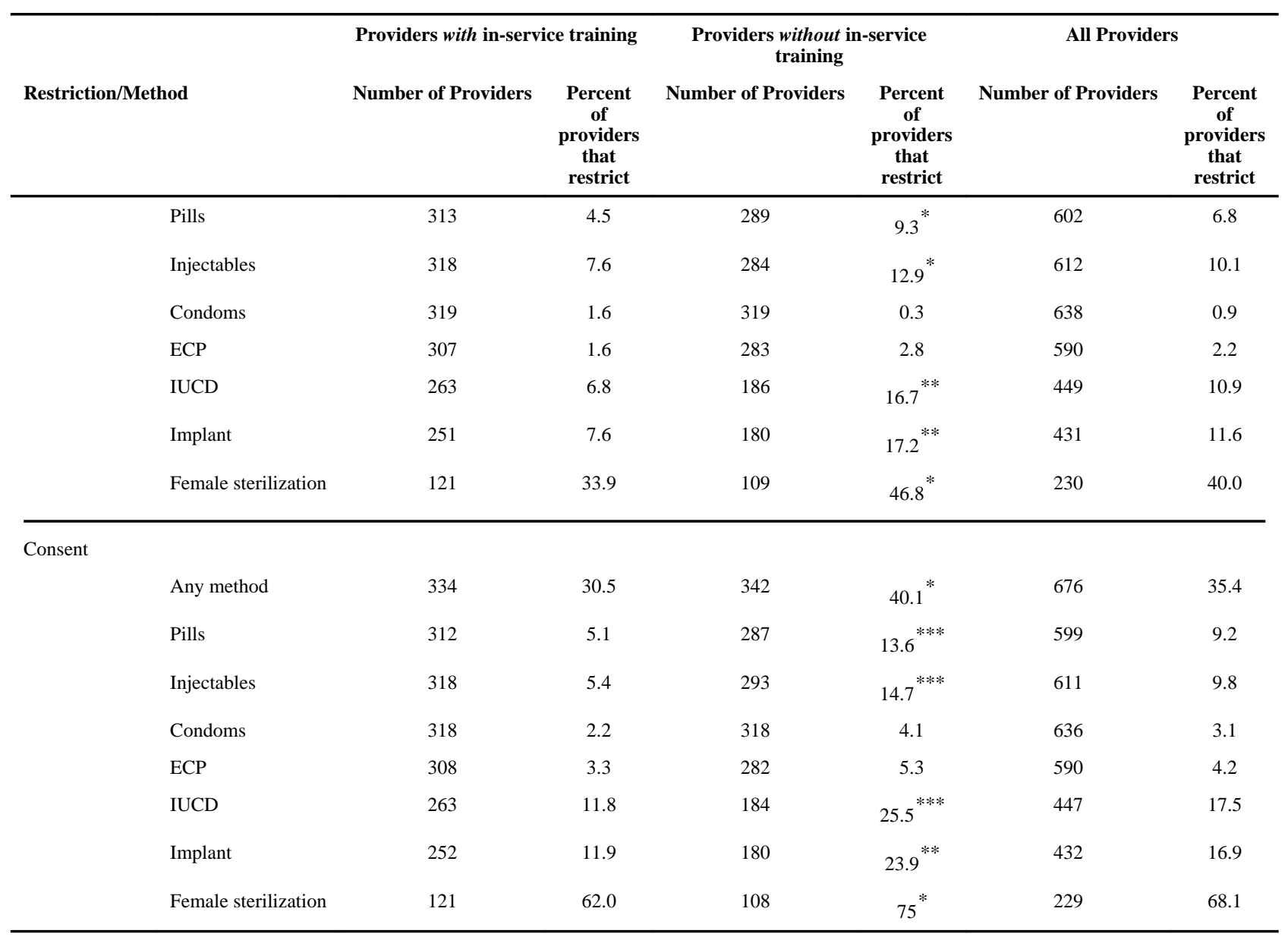

Note: Not all providers offer all methods of family planning; therefore sample sizes vary by method

Note: Variation in sample sizes within methods reflect nonresponse or missing data for some questions

* Chi-square test significant at $\mathrm{p}<.05$

** $\mathrm{p}<.01$

$* * *$

p $<.001$ between those providers with and those without in-service training in family planning provision 